\title{
Early maternal deprivation affects dentate gyrus structure and emotional learning in adult female rats
}

\author{
Charlotte A. Oomen • Heleen Soeters $\cdot$ Nathalie Audureau $\cdot$ Lisa Vermunt • \\ Felisa N. van Hasselt • Erik M. M. Manders • Marian Joëls • Harm Krugers • \\ Paul J. Lucassen
}

Received: 30 March 2010 /Accepted: 9 June 2010 / Published online: 30 June 2010

(C) The Author(s) 2010. This article is published with open access at Springerlink.com

\begin{abstract}
Rationale Stress elicits functional and structural changes in the hippocampus. Early life stress is one of the major risk factors for stress-related pathologies like depression. Patients suffering from depression show a reduced hippocampal volume, and in women, this occurs more often when depression is preceded by childhood trauma. However, the underlying mechanisms that account for a reduced hippocampal volume are unknown.

Objective We examined the effects of maternal absence on structure and function of the hippocampus in female offspring.

Methods We studied whether $24 \mathrm{~h}$ of maternal deprivation (MD) on postnatal day 3 altered adult neurogenesis, individual neuronal morphology and dentate gyrus (DG) structure in young adult female rats. In addition, functional alterations were addressed by studying synaptic plasticity in vitro, and spatial as well as emotional learning was tested. Results Adult females that were subjected to MD revealed significant reductions in DG granule cell number and density. In addition, DG neurons were altered in their
\end{abstract}

C. A. Oomen $(\bowtie) \cdot$ H. Soeters $\cdot$ N. Audureau $\cdot$ L. Vermunt $\cdot$

F. N. van Hasselt $\cdot$ M. Joëls $\cdot$ H. Krugers $\cdot$ P. J. Lucassen

Swammerdam Institute for Life Sciences,

Center for Neuroscience, University of Amsterdam,

Amsterdam, The Netherlands

e-mail: c.a.oomen@uva.nl

P. J. Lucassen

e-mail: P.J.Lucassen@uva.nl

E. M. M. Manders

Center for Advanced Microscopy, University of Amsterdam,

Amsterdam, The Netherlands

M. Joëls

Rudolf Magnus Institute for Neurosciences, UMC Utrecht,

Utrecht, The Netherlands dendritic arrangement. No effects on the rate of adult neurogenesis were found. Furthermore, MD did not alter synaptic plasticity in vitro, neither under normal nor highstress conditions. In addition, spatial learning and contextual fear conditioning were comparable between control and MD animals. However, MD animals showed an improved amygdala-dependent fear memory.

Conclusion Although early life stress exposure did not impair hippocampus-dependent functioning in female offspring, it irreversibly affected DG structure by reducing cell numbers. This may be relevant for the reduced hippocampal volume observed in depression and the increased vulnerability of women to develop depression.

Keywords Rats $\cdot$ Females $\cdot$ Maternal deprivation $\cdot$ Stress . Dentate gyrus · Hippocampus · Adult neurogenesis . Long-term potentiation $\cdot$ Learning and memory

\section{Introduction}

Epidemiological studies suggest that major depression is more prevalent in women than in men (Bland 1997; Kessler et al. 1993; Ustun 2000). However, the exact neurobiological mechanisms that may account for this selective vulnerability remain unknown. The hippocampus, a brain region involved in learning and memory, is susceptible to the effects of stress and shows a reduced volume in depressive patients (Axelson et al. 1993; Bremner et al. 2000; Campbell et al. 2004; Janssen et al. 2004; Sheline et al. 1999; Videbech and Ravnkilde 2004). Interestingly, hippocampal volume reduction particularly occurred in women who were exposed to early childhood trauma (Vythilingam et al. 2002). This suggests that early life stress - possibly via changes in hippocampus structure and function-forms a risk factor for the development of 
stress-related disorders in adult individuals (Heim and Nemeroff 2001; Heim et al. 2000; McEwen 2003; Rao et al. 2010) and particularly in women.

Early life stress in rodents can be induced by maternal separation (MS) or maternal deprivation (MD), i.e. the removal of the dam for a given period of time ( $>3$ or $24 \mathrm{~h}$, respectively) during the first two postnatal weeks (Lehmann and Feldon 2000; Levine et al. 1991). MS and MD were shown to increase corticosterone levels during the early postnatal period (Rosenfeld et al. 1992; Schmidt et al. 2004; Stanton et al. 1988) and can programme hypothalamic-pituitary-adrenal axis function later in life (Lehmann et al. 2002; Plotsky and Meaney 1993; Workel et al. 2001). Interference during the first two postnatal weeks may therefore be of particular relevance for the maturation of the dentate gyrus, a sub-region of the hippocampus that develops for the larger part postnatally (Altman and Bayer 1990a, b). In addition to this, the dentate gyrus exhibits lifelong structural plasticity in the form of adult neurogenesis, a process that has been implicated in hippocampus-dependent learning and memory (Deng et al. 2010; Dupret et al. 2007; Kempermann 2005; Leuner and Gould 2010). These young, adult-born granule cells contribute significantly to behavioural functions such as contextual fear memory, spatial pattern separation and spatial learning (Clelland et al. 2009; Kitamura et al. 2009; Saxe et al. 2006). The role of neurogenesis in stress-related pathology is still under debate (Lucassen et al. 2010a; Sahay and Hen 2007), but neurogenesis seems required for the behavioural effects of (certain) antidepressants in animal studies (Santarelli et al. 2003; Surget et al. 2008).

Surprisingly - given the relevance of structural changes in conjunction with early life stress for depression in women-little is known on how exposure to early life stress affects DG structure and function in (adult) female offspring (Andersen and Teicher 2004; Petersen et al. 2008). Recently, it was reported that adult female rats suffer from memory impairments and depressive-like behaviour in adulthood after early life stress, indicating that females are affected functionally by these stressors (Aisa et al. 2008). In a previous study from our group, we found that early maternal deprivation $(24 \mathrm{~h}$ at postnatal day (PND) 3) reduces the number of immature neurons in the dentate gyrus of the hippocampus in young (PND 21) female, but not male rats (Oomen et al. 2009). This suggested that females apparently respond strongly to a severe early life stressor, which may render them sensitive to hippocampal dysfunction in adulthood. Here, we tested if hippocampal function and structure in female rats exposed to MD is indeed compromised at an adult age. Therefore, we examined the effects of $24 \mathrm{~h}$ MD on PND 3, a critical time point in dentate gyrus maturation (Altman and Bayer 1990a, b), on adult neurogenesis and granule cell morphology. Furthermore, we addressed lasting functional consequences of MD during development, by studying spatial and emotional learning in vivo and synaptic plasticity in vitro, both under stressful and neutral conditions.

\section{Materials and methods}

Animals and breeding procedure

All animal procedures presented in this paper were in compliance with the principles of laboratory animal care and were approved by the animal ethics committee of the University of Amsterdam, The Netherlands. To minimise variation and to avoid stress in the perinatal environment, all animals were bred in-house. Wistar rats were purchased from Harlan (Zeist, The Netherlands), kept under standard housing conditions (dark/light phase $12: 12$, lights on at 8 a.m., humidity $55 \pm 15 \%$, temperature $20-22^{\circ} \mathrm{C}$ ) and habituated to the animal facilities for 10 days. For breeding, one male rat was put together with two females for a period of 1 week.

After mating, females were pair-housed until the beginning of the third gestational week. Then, females were individually housed with extra bedding material and monitored for birth each morning at 9 a.m. If a litter was found, the previous day was designated PND 0, day of birth. Dams with litters were left undisturbed until PND 3 and then randomly assigned to one of the two experimental (MD or control (CON)) groups, making sure that litters from the same father were not in the same experimental group.

\section{Maternal deprivation procedure}

On the morning of PND 3 (9 a.m.), litters were separated from their mother as a whole, shortly handled, culled to four males and four females, and placed back into their home cage. The cage was placed on a heating pad in another room to avoid disturbance by vocalisation in the breeding room. The dam was housed in a novel cage and returned to the breeding room. Litters were kept warm by placing them on a heating pad set at a temperature of $32^{\circ} \mathrm{C}$ during the $24-\mathrm{h}$ deprivation period. Litters were, with the exception of two litters of six pups, larger than or equal to eight pups, with an average of $11 \pm 2$ pups. Due to large litter size, culling to four males and four females was usually possible. In this study, we repeated the exact same experimental procedure as in our previous study (Oomen et al. 2009). No pups were lost during the MD procedure. 
At 9 a.m. on PND 4, cages were cleaned by replacing some of the sawdust, after which the dam was returned to the nest. Litters from the CON group were culled and partially cleaned at the moment of disturbance on PND 3 (11 a.m.). Cages were placed back into the breeding room and left undisturbed until weaning, with the exception of PND 14, when some of the sawdust was replaced. On PND 21, pups were weaned and housed in groups of four same-sex littermates for experiments I, II, III and IV, or in pairs for experiment V. Only results obtained with the female offspring were analysed for the present study.

Experiment I. Baseline and stress-induced corticosterone levels

To investigate effects of early life stress on baseline corticosterone levels, 8- to 13-week-old CON $(n=30)$ and MD $(n=23)$ rats were sacrificed by rapid decapitation between 9 and 10 a.m. Trunk blood was collected in EDTA-covered tubes, centrifuged $(5,000 \mathrm{rpm}$ for $20 \mathrm{~min})$ and blood plasma was stored at $-20^{\circ} \mathrm{C}$ until further processing. To investigate the effects of early life stress on stress-induced corticosterone levels, we induced stress by (1) exposing animals to an adverse novel situation and (2) by exposing them to swimming in a water maze setup. Both these stressors bear relevance to the behavioural tasks in experiment IV. In detail, stressinduced corticosterone levels were measured in a different cohort of $\mathrm{CON}(n=8)$ and $\mathrm{MD}(n=9)$ rats of 14-16 weeks of age by means of the following procedure. In the morning (between 9 and 10 a.m.), rats were brought to a novel room where a baseline blood sample was collected by tail bleeding from a small incision made halfway along the tail (Fluttert et al. 2000). Blood was collected in an EDTA-covered capillary tube. Thirty minutes later, rats were brought to the same room to collect a second sample by means of tail bleeding, which was taken as the stress-induced blood sample. Blood was processed and stored as described above.

Two weeks later, plasma corticosterone levels were determined $1 \mathrm{~h}$ after swim stress in the same animals in order to gain more information about the speed of recovery from a stressor. For this reason, rats were placed into a water maze $\left(22^{\circ} \mathrm{C}, 150 \mathrm{~cm}\right.$ in diameter, no platform present) for $2 \mathrm{~min}$ between 9 and 10 a.m. After this, rats were taken out of the water and placed back into their home cage. One hour after swim stress, rats were decapitated and trunk blood was collected and processed as described above. Plasma corticosterone concentrations from all three experiments were measured in duplicate using a commercially available radioimmunoassay kit (MP Biochemicals, Amsterdam, The Netherlands).
Experiment II. Adult neurogenesis and granule cell morphology

In order to determine lasting effects of early MD on the different stages of the adult neurogenesis process, eight $\mathrm{CON}$ and eight MD females (from four $\mathrm{CON}$ and four MD litters) were injected with bromodeoxyuridine (BrdU; Sigma-Aldrich, $200 \mathrm{mg} / \mathrm{kg}$ body weight, intraperitoneally) on PND 51 and sacrificed 18 days later. At that day, animals were anaesthetised in the morning by an injection of pentobarbital sodium salt (Nembutal, $1 \mathrm{mg} / \mathrm{kg}$ bodyweight; A.U.V. Cuijk, The Netherlands) and perfused transcardially with saline followed by $4 \%$ paraformaldehyde in phosphate buffer (PB; $0.1 \mathrm{M}$; $\mathrm{pH}$ 7.4). To prevent pressure artefacts, brains were post-fixed overnight in the skull at $4{ }^{\circ} \mathrm{C}$ after which they were carefully removed, washed and cryoprotected by $20 \%$ sucrose in phosphate-buffered saline. Frozen sections (30 $\mu \mathrm{m}$ thick) were cut using a sliding microtome and collected in PB with azide.

Different stages of neurogenesis were studied as described previously (Mayer et al. 2006; Oomen et al. 2007). Immunohistochemistry for BrdU (monoclonal murine antiBrdU; Roche Diagnostics, The Netherlands, 1:2,000) was used to primarily assess newborn cell survival. The marker $\mathrm{Ki}-67$, a cell cycle-related protein identifying all cells actively engaged in the cell cycle (polyclonal rabbit $\alpha$-Ki67; Novocastra, Newcastle, UK, 1:2,000), was used to assess cell proliferation. In addition, the number of young, differentiating neurons was identified with an antibody against the microtubule-associated protein doublecortin (DCX; polyclonal goat $\alpha$-DCX, Santa Cruz, 1:800). Amplification was performed with a biotinylated secondary antibody (sheep anti-mouse (1:200; GE Healthcare), goat anti-rabbit (1:200; Vector) and donkey anti-goat (1:500; Jackson), respectively) and avidin-biotin complex (ABC kit; Elite Vectastain, Brunschwig Chemie, Amsterdam, The Netherlands, 1:1,000) in combination with tyramide (1:500; $0.01 \% \mathrm{H}_{2} \mathrm{O}_{2}$ kindly provided by Dr. I. Huitinga, Netherlands Institute for Neuroscience). Subsequent chromogen development was done with diaminobenzidine $(20 \mathrm{mg} / 100 \mathrm{ml} \mathrm{TB}$, $0.01 \% \mathrm{H}_{2} \mathrm{O}_{2}$ ).

All histological quantification procedures described below were performed in a stereological approach in a one-in-ten series of coronal sections taken along the entire rostrocaudal axis in a total of nine sections per animal. The total number of DG granule neurons and DCX-positive cells were quantified by systematic random sampling performed with the StereoInvestigator system (Microbrightfield, Germany). The optical fractionator settings were as follows: for DCX cell count, grid size $140 \times 80$, counting frame $50 \times 50$, which resulted in 300-500 markers per animal; for total granule cell count, grid size $150 \times 150$, 
counting frame $15 \times 15$, which resulted in $300-500$ markers per animal.

Because of the relatively sparse occurrence and frequent clustering of Ki-67-positive and BrdU-positive cells, these cells were counted manually by means of a modified stereological procedure using a Zeiss microscope $(\times 200$ magnification) and multiplied by 10 to estimate the total number of Ki-67-positive and BrdU-positive cells in the DG (Oomen et al. 2007; van Praag et al. 1999). Dentate gyrus granule cell layer (GCL) and molecular layer surface area and volume measurements were performed according to Cavalieri's principle using the appropriate tools for this in the StereoInvestigator system.

Effects of maternal deprivation on the individual granule cell morphology were determined by analysing the dendritic tree of Golgi-stained neurons using 3D reconstruction software. For this purpose, 8- to 13-weekold CON $(n=7)$ and MD $(n=7)$ animals were decapitated in the morning between 9 and 10 a.m., and trunk blood was collected in EDTA-covered tubes (experiment I). Immediately after decapitation, brains were rapidly removed and cut into two hemispheres. One hemisphere was used for Golgi-Cox impregnation and the other for electrophysiological recordings (experiment IV).

For Golgi-Cox impregnation, a similar procedure was used as described previously (Bagot et al. 2009; Boekhoorn et al. 2006; Champagne et al. 2008). Immediately after decapitation, brains were incubated in a Golgi-Cox solution $\left(5 \% \mathrm{~K}_{2} \mathrm{CrO}_{4}, 5 \% \mathrm{HgCl}\right.$ and $\left.5 \% \mathrm{~K}_{2} \mathrm{Cr}_{2} \mathrm{O}_{7}\right)$ for 28 days, after which they were imbedded in celloidin and cut into 200$\mu \mathrm{m}$-thick sections. From each animal, Z-stacks (step size $1 \mu \mathrm{m})$ from five to seven dentate granule cells were generated using a confocal microscope (LSM510, Zeiss, Germany $)$ in bright field mode $(\times 20$ objective $)$ and reconstructed in ImagePro in combination with the Neurodraw toolbox (kindly provided by G. Ramakers, J. van Heerikhuize and C. Pool, Netherlands Institute for Neuroscience, Amsterdam). Criteria for inclusion were as follows: (1) only neurons from the supra-pyramidal blade of the rostral dentate gyrus, from bregma -2.5 to -4.0 (Paxinos and Watson 1986), were selected; (2) cells had to be evenly filled, without any severed dendrites exiting the section; and (3) only cells from the middle third of the granular cell layer were chosen to avoid the inclusion of relatively young or newborn granule cells residing in the inner part of the cell layer, or cells formed early in ontogeny (E21-22) which reside in the outer third part of the cell layer (Altman and Bayer 1990a, b). Total dendritic length, number of branch points and the number of primary dendrites were analysed for every neuron. In addition, spine density was determined in two segments of dendrites at a distance of 90-110 $\mu \mathrm{m}$ (proximal) and 190$210 \mu \mathrm{m}$ (distal) from the soma.
Experiment III. Electrophysiological properties of the dentate gyrus

To determine the effects of maternal deprivation on electrophysiological properties of the DG network, 598 to 13-week-old female rats ( $n=7$ or eight per group) were decapitated in the morning between 9 and 10 a.m. For these experiments, stress from individual housing was avoided by decapitating the last two animals from the same cage simultaneously. Immediately after decapitation, the brain was rapidly removed and cut into two hemispheres. The left hemisphere was collected for Golgi-Cox impregnation (experiment III) and the right hemisphere was collected for electrophysiological recordings in ice-cold artificial cerebrospinal fluid (aCSF) containing $120 \mathrm{mM} \mathrm{NaCl}$, $3.5 \mathrm{mM} \mathrm{KCl}, 1.3 \mathrm{mM} \mathrm{MgSO}{ }_{4} \cdot 7 \mathrm{H}_{2} \mathrm{O}, 1.25 \mathrm{mM} \mathrm{NaH}_{2} \mathrm{PO}_{4}$, $2.5 \mathrm{mM} \mathrm{CaCl} 2 \cdot 2 \mathrm{H}_{2} \mathrm{O}, 10 \mathrm{mM}$ glucose and $25 \mathrm{mM}$ $\mathrm{NaHCO}_{3}$, oxygenated with $95 \% \mathrm{O}_{2}$ and $5 \% \mathrm{CO}_{2}$. Coronal slices $(400 \mu \mathrm{m})$ were cut using a vibratome (Leica VT1000S) at $5^{\circ} \mathrm{C}$ and then kept in oxygenated aCSF at room temperature for at least $2 \mathrm{~h}$ prior to recording. Sections containing the rostral part (bregma -2.5 to -4.0 ; Paxinos and Watson 1986) of the hippocampal dentate gyrus were placed in a recording chamber maintained at $30-32^{\circ} \mathrm{C}$ with a constant flow of oxygenated aCSF.

Field excitatory postsynaptic potentials (fEPSPs) were recorded as previously described (Bagot et al. 2009; Pu et al. 2007) in the absence or presence of the GABAergic antagonist bicuculline methiodide (Tebu-bio, $10 \mu \mathrm{M}$ ). fEPSPs were evoked using a stainless steel bipolar stimulation electrode $(60 \mu \mathrm{m}$ diameter, insulated except for the tip) positioned in the medial perforant pathway and recorded through a glass electrode (2-5 M $\Omega$ impedance, filled with aCSF) positioned in the middle third of the molecular layer of the upper blade. A stimulus-response curve was generated by gradually increasing the stimulus intensity to define a level that generated the half-maximal response which was used for the remainder of the experiment. Once the input-output curve for each recording was established, baseline synaptic transmission was monitored $(0.017 \mathrm{~Hz})$ during $20 \mathrm{~min}$.

When recordings were stable, theta burst stimulation (TBS; four pulses of $100 \mathrm{~Hz}$ followed by a 200-ms interval, followed by another four pulses) was applied. This sequence was repeated five times with a 30-s interval. After TBS, the degree of potentiation was determined by recording the fEPSP every minute during $1 \mathrm{~h}(0.017 \mathrm{~Hz})$. The magnitude of the fEPSP was assessed by analysing the slope of the signal. To determine whether the presence of the stress hormone corticosterone during stimulation modulates the degree of long-term potentiation (LTP), corticosterone (SigmaAldrich, The Netherlands; $100 \mathrm{nM}$, dissolved in $0.01 \%$ 
ethanol) or vehicle $(0.01 \%$ ethanol) was added to the aCSF during the second half of baseline recordings ( $t=-10$ to $0 \mathrm{~min}$ ), co-terminating with TBS (Bagot et al. 2009). This concentration of corticosterone was shown before to occupy both MR and GR and is therefore comparable and relevant to mimic in vivo stressful situations (Champagne et al. 2008; Karst et al. 2000).

\section{Experiment IV. Spatial and emotional learning}

One cohort of animals (ten CON and ten MD rats) was used for three behavioural tasks described in the following section. Animals were housed in pairs. During testing, rats from the same home cage were tested on different days to avoid effects of acute stress. Before and in between tasks, rats were handled every other day, starting 2 weeks before the start of the first experiment. The order of testing was as described below, and the time in between tasks was at least 1 week.

To study potential changes in basal exploration and anxiety levels after maternal deprivation, CON $(n=10)$ and MD $(n=10)$ rats were tested in an elevated plus maze at the age of 11 weeks. For this, each rat was transferred from its home cage to the experimental setup in an adjacent room. In this testing room, animals were put on the centre of a plus maze ( $100 \mathrm{~cm}$ from the ground), facing one of the two open arms. The plus maze was made of black plastic and shaped like a cross with two opposite open arms $(10 \times 40 \mathrm{~cm})$ and two opposite closed arms $(10 \times 40 \mathrm{~cm}, 25-\mathrm{cm}$-high walls $)$ connected to an open centre. Animals were placed in the centre and allowed to freely explore the open and closed arms for $5 \mathrm{~min}$. Exploration patterns were recorded by a video camera coupled to a computer and processed by Ethovision (Noldus, Wageningen, The Netherlands). Total time, frequency and latency to first appearance in all compartments of the maze were analysed to determine the exploration pattern.

To determine spatial learning ability of MD rats, animals were trained in a Morris water maze (Morris 1984). CON $(n=10)$ and MD $(n=10)$ animals (13 weeks old) were trained in 2 days, during which they received four trials per day with an inter-trial interval of $15 \mathrm{~min}$. The water maze $(150 \mathrm{~cm}$ in diameter) was situated in a room adjacent to where animals were housed and filled with opaque water $\left(22^{\circ} \mathrm{C}\right.$, with added non-toxic paint). In one quadrant (NW), a transparent platform $(12 \mathrm{~cm}$ in diameter) was hidden $0.5 \mathrm{~cm}$ under the water surface. During training, trials were started in one of the three quadrants without platform (i.e. NE, SW or SE quadrant) and starting position alternated between trials, rats and days. At the start of each trial, rats were placed in the water facing the wall of the pool. Animals were allowed to swim in the maze until they had reached the platform or until a maximum time of $2 \mathrm{~min}$ had passed. When rats were unable to find the platform, they were guided there manually. Animals were left on the platform for an additional $20 \mathrm{~s}$. Trials were recorded and analysed for latency, swim distance and time in the platform quadrant (Ethovision; Noldus).

To assess hippocampus- and amygdala-dependent emotional memory, rats were subjected to contextual and cued fear conditioning (Phillips and LeDoux 1992; Zhou et al. 2009). During fear conditioning, 15-week-old rats $(\mathrm{CON}=10 ; \mathrm{MD}=10)$ learned to associate a fearful stimulus (foot shock) with a context (conditioning box) and a cue (tone). The strength of fear-associated memory was determined by measuring the amount of freezing behaviour. Scoring was done manually, every $2 \mathrm{~s}$, by two observers blinded to the experimental group. Rats were habituated to the experimental room starting 2 days before conditioning. Animals were trained by placing them in the fear conditioning box $(30 \times 26 \times 24 \mathrm{~cm}$, walls made of black and transparent plastic with metal grid floor) in which they were allowed to explore freely for $3 \mathrm{~min}$. After that, a 30 -s tone was played $(100 \mathrm{~dB}, 2.8 \mathrm{kHz})$ that coterminated with a foot shock $(12 \mathrm{~s}, 0.4 \mathrm{~mA})$. On the second day at the same time, animals were put into the conditioning box for $3 \mathrm{~min}$ under identical circumstances (i.e. the same cleaning solvent, lighting conditions, gloves and lab coats). Contextual memory was evaluated by scoring freezing behaviour. Two hours later, cued memory was tested by placing rats in a different box, with a solid white floor and light-coloured walls under changed circumstances (i.e. different cleaning solvent, lighting conditions, gloves and lab coat). Again, rats were allowed to explore the box freely for $3 \mathrm{~min}$, after which the tone was presented for $30 \mathrm{~s}$. Rats remained in the box for an additional $60 \mathrm{~s}$ to determine the behavioural response to the cue.

\section{Statistical analysis}

Statistical analysis was performed using SPSS 16.0. All data are presented as average \pm SEM. Differences between $\mathrm{CON}$ and MD animals concerning body weight, corticosterone levels, levels of neurogenesis (all expressed per hemisphere), morphological parameters and water maze probe trial were tested for significance using a two-tailed Student's $t$ test with a probability level of $5 \%$, after determining equality of variances using Levene's test (all data $p>0.05$ ).

Differences in acquisition of the water maze, contextdependent freezing and cue-dependent freezing were tested with a single-factor repeated measures ANOVA using early life treatment as a between-subjects factor. Within-subjects factors were used: trial (water maze), 
consecutive time interval (contextual fear conditioning) and before-tone vs. after-tone interval (cued fear conditioning), respectively.

Effects of corticosterone treatment on baseline synaptic transmission were tested by comparing the average slope of the fEPSP of the first baseline $(-20$ to $-10 \mathrm{~min})$ with the average of the second baseline $(-10$ to $0 \mathrm{~min})$ using a three-factor repeated measures ANOVA (between-subjects factors: early life treatment and drug treatment; within-subjects factor: baseline). To determine the effects of early life stress and application of the stress hormone corticosterone on the degree of LTP, a threefactor repeated measures ANOVA was performed using early life treatment and corticosterone treatment as between-subjects factors and pre- or post-TBS as within-subjects factor. We compared the second baseline ( -10 to $0 \mathrm{~min})$ with early LTP $(0-30 \mathrm{~min}$ post-TBS) and total LTP (0-60 min post-TBS). When significant, a post hoc LSD test was performed to compare treatment groups.

\section{Results}

Experiment I. Body weight and basal corticosteroid levels are reduced by MD

On PND 51, MD females had significant ( $p=0.003)$ lower bodyweights $(171 \pm 3 \mathrm{~g}, n=8)$ compared to $\mathrm{CON}$ females $(194 \pm 6 \mathrm{~g}, n=8)$. Although we have no explanation for the lasting reduction in body weight, it is possible that 24-h maternal deprivation at PND 3 programmes metabolism in such a way that body weight is persistently reduced. In addition, basal corticosterone levels were significantly lower in MD $(47 \pm 11 \mathrm{ng} / \mathrm{ml})$ than in CON $(127 \pm 23 \mathrm{ng} / \mathrm{ml})$ animals $(p=0.002)$. Thirty minutes after a moderate stressor (tail nick), corticosterone levels were elevated in both groups. Although at that time point plasma corticosterone levels were higher in CON than MD animals $(639 \pm 129 \mathrm{ng} / \mathrm{ml}$ $(n=8)$ vs. $373 \pm 101 \mathrm{ng} / \mathrm{ml}(n=9)$, respectively), this difference did not reach significance $(p=0.2)$. One hour after swim stress, both CON $(482 \pm 87 \mathrm{ng} / \mathrm{ml}, n=10)$ and MD $(302 \pm$ $102 \mathrm{ng} / \mathrm{ml}, n=10)$ rats showed similar elevations in corticosterone level $(p=0.2)$.

Experiment II. Maternal deprivation only mildly affects neurogenesis, cell morphology and dentate gyrus architecture

Stereological quantification of several phases of adult neurogenesis in the dentate gyrus revealed no significant effects of MD on the total numbers of proliferating cells (Ki-67+), on the number of 18-day-old newborn (BrdU+)
Table 1 Effects of MD on adult neurogenesis

\begin{tabular}{lcc}
\hline & CON $(n=8)$ & MD $(n=8)$ \\
\hline Proliferation (Ki-67) & $2,843 \pm 264$ & $2,661 \pm 206$ \\
Cell survival (BrdU) & $1,703 \pm 120$ & $1,588 \pm 103$ \\
Neuronal differentiation (DCX) & $32,769 \pm 2,594$ & $29,343 \pm 2,143$
\end{tabular}

Absolute cell numbers per hemisphere were not significantly different between CON and MD animals $(p>0.1)$

cells and on the number of young neurons (DCX+) reflecting neurogenesis (Table 1). Further detailed analysis was performed by comparing total cell numbers according to their distribution along the rostrocaudal axis, between the supra- and infra-pyramidal blade and as a percentage of total cells. This also did not reveal any significant differences.

While neurogenesis was not affected by maternal deprivation, stereological quantification of the number of DG granule neurons revealed that maternal deprivation significantly reduced the total cell number $(p=0.04)$ and cell density $(p=0.03)$ in the GCL by about $12 \%$ (Fig. 1a, b), without affecting granular cell layer volume (CON $1.03 \pm$ $0.03 \mathrm{~mm}^{3}$; MD $1.05 \pm 0.02 \mathrm{~mm}^{3}, p=0.51$ ) or the volume of the molecular layer (CON $3.26 \pm 0.16 \mathrm{~mm}^{3}$; MD $3.25 \pm$ $\left.0.08 \mathrm{~mm}^{3}, p=0.94\right)$.

Morphological analysis of the Golgi-stained individual neurons revealed a change in the dendritic arrangement, but not total dendritic length, number of branch points or spine density in females subjected to MD (Table 2). The average number of primary dendrites extending from the soma was increased $(p=0.02)$ in MD animals when compared to controls.
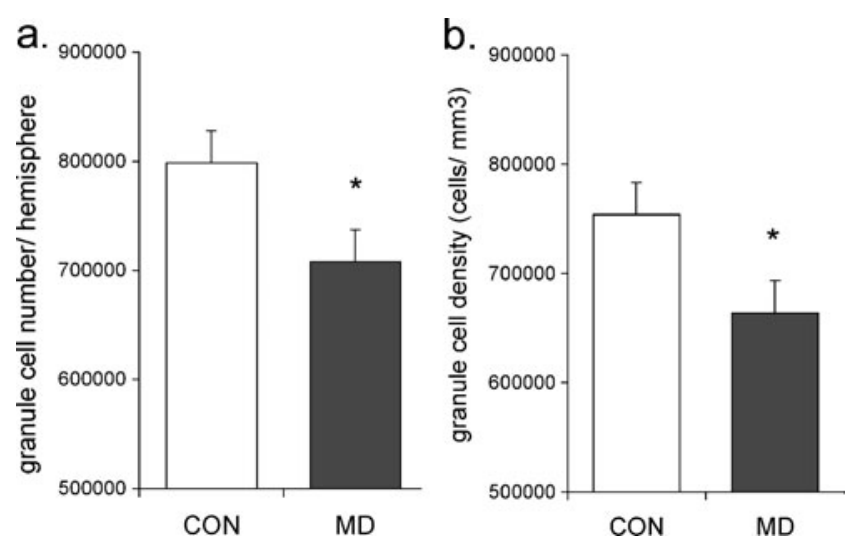

Fig. 1 Effects of MD on the granule cell layer of the hippocampal dentate gyrus. a MD treatment caused a significant reduction in absolute granule cell numbers $(p=0.04)$ as well as $\mathbf{b}$ cell density $(p=0.03$; both groups $n=8$ ) 
Table 2 Effects of MD on granule cell morphology

\begin{tabular}{lcc}
\hline & CON $(n=7)$ & MD $(n=7)$ \\
\hline Dendritic length $(\mu \mathrm{m})$ & $1,560 \pm 130$ & $1,592 \pm 121$ \\
Number of branch points & $8.6 \pm 0.6$ & $7.0 \pm 0.6$ \\
Spine density (number of spines $/ \mu \mathrm{m})$ & $0.63 \pm 0.04$ & $0.59 \pm 0.06$ \\
Number of primary dendrites & $2.3 \pm 0.2$ & $3.1 \pm 0.2^{*}$ \\
\hline
\end{tabular}

MD treatment resulted in an increased average number of primary dendrites per cell $(n=7$ animals per group, values based on five to seven granule cells per animal)

$* p<0.05$

Experiment IV. Maternal deprivation does not alter synaptic plasticity

To examine whether morphological changes in the dentate gyrus affected hippocampal synaptic function, we examined LTP in the dentate gyrus using TBS. TBS in the absence of bicuculline did neither in CON nor in MD animals result in synaptic potentiation (data not shown). In addition, the presence of the stress hormone corticosterone prior to and during TBS did not change this (repeated measures ANOVA baseline vs. post-TBS (1-60 min), $F_{1,16}=0.9 ; p=0.36$; CON and MD animals pooled). This is not unprecedented since GABAergic innervation is known to drive dentate granule cells in vitro away from their firing threshold (Coulter and Carlson 2007; Wisden et al. 1992). Therefore, we applied TBS in the presence of the GABAergic antagonist bicuculline, which resulted in an overall significant induction of LTP (pooled data from CON and MD rats; repeated measures ANOVA $F_{1,28}=18.3 ; p<0.001$ ). In all experiments described below, bicuculline was present. We found no differences between CON and MD animals in the maximum amplitude of the fEPSP (CON $-2.49 \pm$ $0.26 \mathrm{mV} ; \mathrm{MD}-2.46 \pm 0.23 ; p=0.50$ ) nor in the stimulation intensity that yielded the half-maximal amplitude (CON $1.93 \pm 0.01$; MD $1.91 \pm 0.02 ; p=0.49)$ as determined from the input-output curve.

The effects of corticosterone on the degree of LTP was determined by perfusion of $100 \mathrm{nM}$ corticosterone during the second half of baseline recordings, co-terminating with the end of TBS. Corticosterone application in itself had no effect on the magnitude of the signal during the second half of baseline recordings, as revealed by a repeated measures ANOVA comparing baseline $1(t=-20$ to $-11 \mathrm{~min})$ with baseline $2(t=-10$ to $0 \mathrm{~min}$; baseline $\times$ drug $\times$ group, $F_{1,28}=2.3, p=0.14$; drug $\times$ group, $F_{1,28}=2.4$, $p=0.14)$. For LTP, no significant effects were found on the degree of potentiation of group (CON vs. MD; $F_{1,28}=$ $0.03 ; p=0.86)$ and drug treatment $\left(F_{1,28}=0.04 ; p=0.84\right)$, nor an interaction effect between these two $\left(F_{1,28}=0.002\right.$;
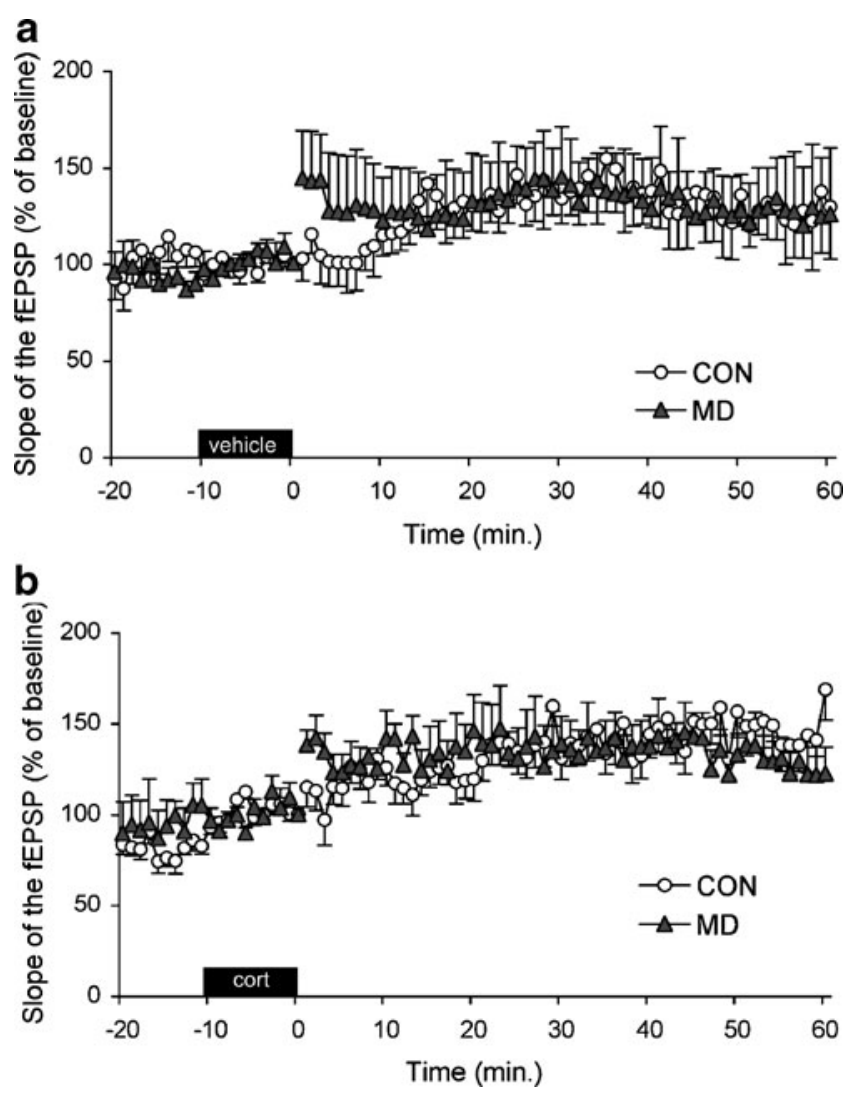

Fig. 2 Effects of MD on synaptic plasticity. a LTP measured under vehicle conditions (CON $n=7, \mathrm{MD} n=7$ ). There was no effect of maternal deprivation on the degree of LTP in the dentate gyrus after theta burst stimulation (CON vs. MD; $F_{1,28}=0.03 ; p=0.86$ ) when comparing the second half of baseline recordings ( $t=-10$ to $0 \mathrm{~min}$ ) with post-TBS recordings. b Long-term potentiation after acute corticosterone application. The degree of LTP was not affected by corticosterone application, and there was no difference between CON $(n=7)$ and $\mathrm{MD}(n=7)$ animals $\left(F_{1,28}=0.04 ; p=0.84\right)$, interaction group $\times$ treatment $\left(F_{1,28}=0.002 ; p=0.96\right)$

$p=0.96$ ), when comparing the second half of baseline recordings $(t=-10$ to $0 \mathrm{~min})$ with post-TBS recordings $(t=0-60$ min; Fig. 2a, b).

Experiment V. MD specifically increases cued fear conditioning

Spatial acquisition of the Morris water maze was not changed by maternal deprivation (Fig. $3 ; F_{1,18}=2.15 ; p=$ 0.16). Furthermore, CON and MD animals showed similar performance in memory retention after 7 days, as measured by the total time spent in the platform quadrant during the probe trial (CON 20.5 $\pm 12.1 \mathrm{~s}(n=10)$, MD $28.5 \pm 16.2 \mathrm{~s}(n=10), p=0.68)$.

Baseline anxiety, determined in the same groups of animals by elevated plus maze exploration, was also not affected by maternal deprivation. There were no significant differences concerning latency to enter (CON $39.0 \pm 15.1 \mathrm{~s}$; 


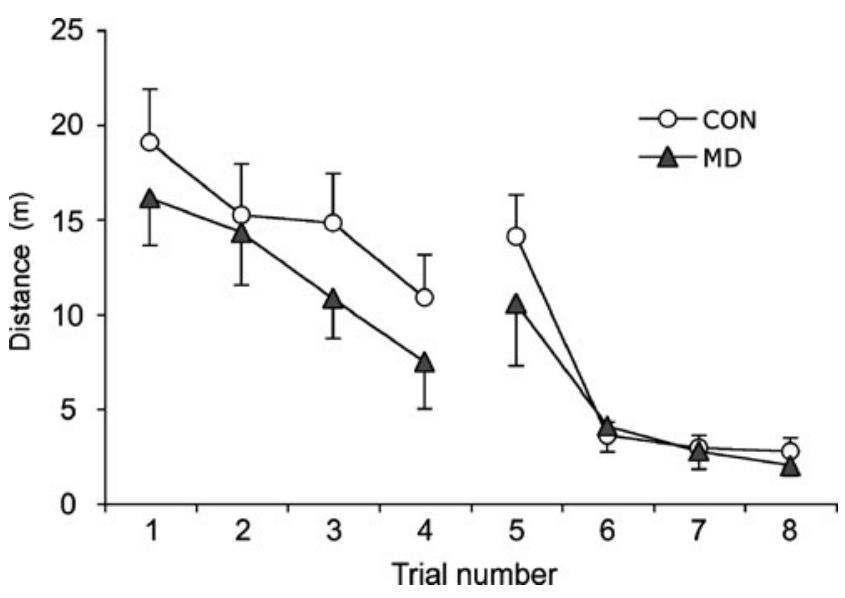

Fig. 3 Effects of MD on water maze acquisition. Travel distance to the hidden platform was similar in both CON and MD animals (both groups $n=10 ; p=0.16$ )

MD $42.5 \pm 12.8 \mathrm{~s}, p=0.70)$, frequency (CON 6.7 \pm 1.4 times; MD 6.6 \pm 1.2 times, $p=0.70$ ) and/or percentage of time spent in the open arms of the maze (CON $38.4 \pm 6.0 \%$; MD $48.7 \pm 7.0 \% ; p=0.37$ ).

Fear conditioning did not reveal any effects of MD on baseline freezing behaviour nor on freezing behaviour during training (data not shown), supporting the notion that MD does not affect overall anxiety in female rats later in life. Twenty-four hours later-during the contextual test -both groups showed comparable freezing behaviour $\left(F_{1,35}=0.92, p=0.35\right.$; Fig. 4a). While contextual fear conditioning was not affected by MD, exposure to a novel environment $24 \mathrm{~h}$ after the cue-shock training did result in elevated levels of freezing in MD compared to $\mathrm{CON}$ animals ( $p=0.002$; Fig. 4 b). Subsequent exposure to the earlier cue in this novel environment caused extensive a.

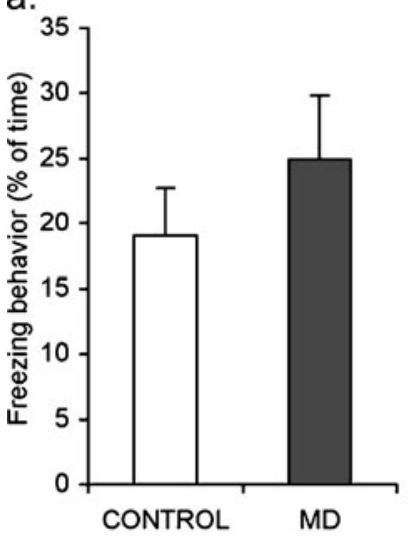

b.

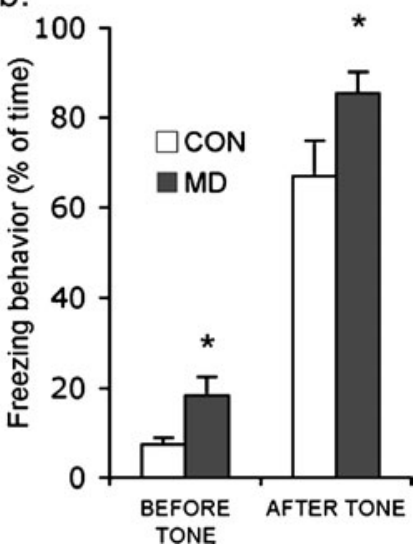

Fig. 4 Effects of MD on fear conditioning. a MD does not affect the amount of freezing behaviour in response to the context $(p=0.35)$. b During cued fear conditioning, MD animals $(n=10)$ show increased freezing in response to the novel environment $(p=0.002)$ and an increased freezing behaviour in response to the tone when compared to controls (both groups, $n=10, p<0.05$ ) freezing behaviour, which also differed significantly between MD and CON animals ( $p<0.05$; Fig. $4 b$ ).

\section{Discussion}

In the present study, we show that a history of early maternal deprivation exerts irreversible effects on hippocampal structure and function in adult female offspring. Adult female rats exposed to MD early in life showed a lower cell number and cell density in the GCL and significant dendritic re-arrangement of DG neurons. No effects of MD at PND 3 were found on hippocampal neurogenesis in adult female rats, indicating that the decreased neurogenesis after MD reported earlier at PND 21 (Oomen et al. 2009) does not last into adulthood. We also observed surprisingly little effect of MD on synaptic plasticity in the DG and on hippocampaldependent learning tasks. While we have no indication that MD alters general anxiety in adult female rats, amygdaladependent fear memory after MD was improved.

Effects of maternal deprivation on structural parameters of the dentate gyrus

In our current MD model of early life stress, rat pups experienced elevated levels of corticosterone (Oomen et al. 2009) during a period that is normally characterised by low corticosterone levels (Levine 2001). This coincides with a crucial period in DG development (Altman and Bayer $1990 \mathrm{a}, \mathrm{b})$ as around this time, extensive migration of the secondary matrix takes place that gives rise to the inner two thirds of the GCL. Previously, we have shown that $24 \mathrm{~h}$ of MD on PND 3 decreases the number of doublecortinpositive cells, i.e. immature neurons, in 3-week-old females (Oomen et al. 2009). Others have shown that MD increases cell death in the infant rat hippocampus, independent of sex (Llorente et al. 2009; Zhang et al. 2002). In addition, on PND 12, a modest increase in DG glia cell number was found after MD on PND 9 (Llorente et al. 2009). Interestingly, neuroprotective effects of calcium-binding proteins in infant rats subjected to MD were only found in male but not female offspring (Lephart and Watson 1999). These cellular effects of MD on the infant female hippocampus during a crucial phase in DG development, in combination with the apparent lack of protective mechanisms in females, may explain the irreversible decrease in GCL number after MD in this study.

Another prominent finding, in addition to the reduction in GCL number and density, is the altered dendritic morphology of the individual DG neuron after early life stress. Females subjected to MD in infancy showed an increased number of primary dendrites extending from the soma, without effects on the total dendritic length. Other 
studies have reported effects of the early life environment on dendritic complexity in various hippocampal sub-fields, but this was mainly done in males and compared either natural levels of maternal care (Bagot et al. 2009; Champagne et al. 2008) or studied low maternal care induced after chronic stress (Brunson et al. 2005). In these studies, a reduction in dendritic mass, dendritic complexity and spine density was found. The results from the present study do not reveal an overall dendritic atrophy or loss of complexity but rather a higher number of primary dendrites, which is usually a sign of more mature neurons (Claiborne et al. 1990). Our results therefore suggest that a surge in postnatal corticosteroid levels due to MD-even though basal hormone levels are lower in adult females-yields fewer granular cells in female offspring. Yet, these cells do have a more mature phenotype.

Functional consequences of maternal deprivation

Chronic early life stress and low levels of maternal care are known to impair LTP in area CA3 (Brunson et al. 2005), CA1 (Champagne et al. 2008) and in the DG (Bagot et al. 2009). MD also impairs stress-induced late-phase LTP reinforcement in the DG (Gruss et al. 2008). However, all these studies were performed in males. In the present study, no effects of MD were found on LTP in the DG of female rats, nor did corticosterone application affect LTP in control or MD animals. This indicates that a reduced GCL number and density and an altered dendritic complexity do not necessarily influence the ability to elicit synaptic plasticity. In this study, we stimulated the medial perforant path and recorded the fEPSP from the molecular layer. A possible explanation for the lack of MD-induced effects on LTP could be that putative effects on synaptic transmission are only expressed at other (presently not investigated) synaptic inputs to the DG. An alternative explanation could be that the changes in DG cell number are compensated for by the changes in dendritic morphology.

In the present study, females exposed to $24 \mathrm{~h} \mathrm{MD}$ on PND 3 were not altered in their performance in the water maze, a spatial learning task dependent on an intact hippocampus (Schenk and Morris 1985). Other studies have shown an impairment of water maze acquisition after MD, but these were mostly carried out in males (Aisa et al. 2007; Choy et al. 2008; Garner et al. 2007; Mello et al. 2009; Oitzl et al. 2000; Uysal et al. 2005). One study regarding the effects of MD on spatial learning in females found an enhanced acquisition (Pryce and Feldon 2003), as opposed to an impairment in males. In our model, we also found such a differential, sex-dependent effect of MD on spatial acquisition since water maze learning was impaired in male offspring after MD (Oomen et al. 2010), but not in females as shown in the current study.
In addition to the water maze data, we found that the memory of a fearful context was unchanged after MD. Our combined electrophysiological and behavioural data therefore suggest that, in female rodents, $24 \mathrm{~h}$ MD at PND 3 does not profoundly alter hippocampal function later in life despite the changes in total cell number and primary dendrites per cell in the DG.

MD females did show an enhanced freezing response to the tone when tested for retention in a cued fear conditioning paradigm. Remarkably, freezing behaviour was already elevated before the tone. This indicates that, after MD, females show overall higher anxiety levels, but this was not confirmed by data on the training phase of fear conditioning, contextual fear conditioning nor by their behaviour in the elevated plus maze. The differences in cue fear conditioning may therefore reflect a specific increase in the memory of emotional events. Fear conditioning can be modulated (to some extent) by changes in the corticosteroid level (Cordero et al. 1998; Pugh et al. 1997), and for this reason, we measured corticosterone levels after exposure to an adverse novel environment in experiment I. Yet, it seems unlikely - although it cannot be ruled out completely - that the effects of MD on cued fear conditioning are mediated by MD-dependent differences in circulating levels of corticosterone at the time of training or retention since we did not observe significant effects of MD on stress-induced corticosterone levels. Instead, we observed decreased basal levels of corticosterone after MD, both at PND 21 and in 2- to 3-month-old female rats. An alternative explanation is that MD may have altered dendritic complexity of principal neurons in the basolateral amygdala, which is believed to be critical for cued memory (LeDoux et al. 1988; Rodrigues et al. 2009).

We here showed that a severe model of early life stress reduces GCL number and density and induces an altered neuronal morphology in the DG of female offspring. This indicates that, although the prominent changes in neurogenesis at 3 weeks after MD (Oomen et al. 2009) normalise, it may eventually have long-lasting consequences for total neuron numbers. Whether similar changes occur with respect to hippocampal volume reduction in depressive patients remains to be shown (Czeh and Lucassen 2007). Analysis of postmortem hippocampus tissue of depressed patients has revealed minor structural alterations at the level of astrocyte (Muller et al. 2001), cytogenesis (Boldrini et al. 2009; Lucassen et al. 2010b) and neuron (Stockmeier et al. 2004) density, but possible changes in total neuron numbers have not been addressed. Such studies are required to reveal a relationship between our observation that early stress in rodents is able to produce irreversible changes in cell numbers of the hippocampus in female offspring and the notion that depressed women-in particular those with a 
history of early stress - were found to have a reduced hippocampal volume (Vythilingam et al. 2002). Also, it should be noted that depressed patients were often exposed to a combination of stress during early life and adulthood; the latter one was not the case in our animal model.

The DG is a filter for incoming information into the hippocampus and is thought to separate (spatial) information input that is highly similar in content, which, in rodents, contributes to (among others) spatial navigation (Scharfman 2007). Changes in DG structure and function may therefore affect downstream processing by the hippocampus; in accordance, alterations in structural plasticity, e.g. adult neurogenesis, have been shown to affect hippocampus-dependent learning and memory also in relation to its functional role as pattern separator (Clelland et al. 2009; Creer et al. 2010). Despite these findings, the structural changes in adult female rats with a history of MD as seen in this study seem to have no major consequences for DG synaptic plasticity or for hippocampus-dependent learning and memory processes, at least not in the presently used tasks. Whether additional challenges at an adult age would induce such deficits awaits future research. Rather, concurrent with the structural changes in the hippocampus, amygdala function may be altered in these females as a consequence of MD. Excessive amygdala activation to fearful situations is a consistent finding in depressed individuals (Abercrombie et al. 1998; Drevets et al. 1992; Leppanen 2006). We therefore speculate that a change in HPA levels due to early life stress may contribute to structural changes in limbic areas. This could eventually cause behavioural dysfunction, particularly the processing of emotional (rather than neutral) events.

Acknowledgements PJL was supported by the Hersenstichting Nederland, the EU (NEURAD consortium), ISAO and the Volkswagen Stiftung Germany; the authors declare that they have no conflict of interest. We would like to thank Els Velzing (Swammerdam Institute for Life Sciences, University of Amsterdam, The Netherlands) for technical assistance, Joop van Heerikhuize (Netherlands Institute for Neuroscience, Amsterdam, The Netherlands) for assistance with the Neurodraw software and Maaike van der Mark (Leiden/ Amsterdam Center for Drug Research, Leiden University, The Netherlands) for the analysis of plasma corticosterone levels.

Open Access This article is distributed under the terms of the Creative Commons Attribution Noncommercial License which permits any noncommercial use, distribution, and reproduction in any medium, provided the original author(s) and source are credited.

\section{References}

Abercrombie HC, Schaefer SM, Larson CL, Oakes TR, Lindgren KA, Holden JE, Perlman SB, Turski PA, Krahn DD, Benca RM, Davidson RJ (1998) Metabolic rate in the right amygdala predicts negative affect in depressed patients. NeuroReport 9:3301-3307
Aisa B, Tordera R, Lasheras B, Del Rio J, Ramirez MJ (2007) Cognitive impairment associated to HPA axis hyperactivity after maternal separation in rats. Psychoneuroendocrinology 32:256266

Aisa B, Tordera R, Lasheras B, Del Rio J, Ramirez MJ (2008) Effects of maternal separation on hypothalamic-pituitary-adrenal responses, cognition and vulnerability to stress in adult female rats. Neuroscience 154:1218-1226

Altman J, Bayer SA (1990a) Migration and distribution of two populations of hippocampal granule cell precursors during the perinatal and postnatal periods. J Comp Neurol 301:365-381

Altman J, Bayer SA (1990b) Mosaic organization of the hippocampal neuroepithelium and the multiple germinal sources of dentate granule cells. J Comp Neurol 301:325-342

Andersen SL, Teicher MH (2004) Delayed effects of early stress on hippocampal development. Neuropsychopharmacology 29:19881993

Axelson DA, Doraiswamy PM, McDonald WM, Boyko OB, Tupler LA, Patterson LJ, Nemeroff CB, Ellinwood EH Jr, Krishnan KR (1993) Hypercortisolemia and hippocampal changes in depression. Psychiatry Res 47:163-173

Bagot RC, van Hasselt FN, Champagne DL, Meaney MJ, Krugers HJ, Joels M (2009) Maternal care determines rapid effects of stress mediators on synaptic plasticity in adult rat hippocampal dentate gyrus. Neurobiol Learn Mem 92:292-300

Bland RC (1997) Epidemiology of affective disorders: a review. Can J Psychiatry 42:367-377

Boekhoorn K, Terwel D, Biemans B, Borghgraef P, Wiegert O, Ramakers GJ, de Vos K, Krugers H, Tomiyama T, Mori H, Joels M, van Leuven F, Lucassen PJ (2006) Improved long-term potentiation and memory in young tau-P301L transgenic mice before onset of hyperphosphorylation and tauopathy. J Neurosci 26:3514-3523

Boldrini M, Underwood MD, Hen R, Rosoklija GB, Dwork AJ, John Mann J, Arango V (2009) Antidepressants increase neural progenitor cells in the human hippocampus. Neuropsychopharmacology 34:2376-2389

Bremner JD, Narayan M, Anderson ER, Staib LH, Miller HL, Charney DS (2000) Hippocampal volume reduction in major depression. Am J Psychiatry 157:115-118

Brunson KL, Kramar E, Lin B, Chen Y, Colgin LL, Yanagihara TK, Lynch G, Baram TZ (2005) Mechanisms of late-onset cognitive decline after early-life stress. J Neurosci 25:93289338

Campbell S, Marriott M, Nahmias C, MacQueen GM (2004) Lower hippocampal volume in patients suffering from depression: a meta-analysis. Am J Psychiatry 161:598-607

Champagne DL, Bagot RC, van Hasselt F, Ramakers G, Meaney MJ, de Kloet ER, Joels M, Krugers H (2008) Maternal care and hippocampal plasticity: evidence for experience-dependent structural plasticity, altered synaptic functioning, and differential responsiveness to glucocorticoids and stress. J Neurosci 28:6037-6045

Choy KH, de Visser Y, Nichols NR, van den Buuse M (2008) Combined neonatal stress and young-adult glucocorticoid stimulation in rats reduce BDNF expression in hippocampus: effects on learning and memory. Hippocampus 18:655-667

Claiborne BJ, Amaral DG, Cowan WM (1990) Quantitative, threedimensional analysis of granule cell dendrites in the rat dentate gyrus. J Comp Neurol 302:206-219

Clelland CD, Choi M, Romberg C, Clemenson GD Jr, Fragniere A, Tyers P, Jessberger S, Saksida LM, Barker RA, Gage FH, Bussey TJ (2009) A functional role for adult hippocampal neurogenesis in spatial pattern separation. Science 325:210-213

Cordero MI, Merino JJ, Sandi C (1998) Correlational relationship between shock intensity and corticosterone secretion on the 
establishment and subsequent expression of contextual fear conditioning. Behav Neurosci 112:885-891

Coulter DA, Carlson GC (2007) Functional regulation of the dentate gyrus by GABA-mediated inhibition. Prog Brain Res 163:235243

Creer DJ, Romberg C, Saksida LM, van Praag H, Bussey TJ (2010) Running enhances spatial pattern separation in mice. Proc Natl Acad Sci U S A 107:2367-2372

Czeh B, Lucassen PJ (2007) What causes the hippocampal volume decrease in depression? Are neurogenesis, glial changes and apoptosis implicated? Eur Arch Psychiatry Clin Neurosci 257:250-260

Deng W, Aimone JB, Gage FH (2010) New neurons and new memories: how does adult hippocampal neurogenesis affect learning and memory? Nat Rev Neurosci 11:339-350

Drevets WC, Videen TO, Price JL, Preskorn SH, Carmichael ST, Raichle ME (1992) A functional anatomical study of unipolar depression. J Neurosci 12:3628-3641

Dupret D, Fabre A, Dobrossy MD, Panatier A, Rodriguez JJ, Lamarque S, Lemaire V, Oliet SH, Piazza PV, Abrous DN (2007) Spatial learning depends on both the addition and removal of new hippocampal neurons. PLoS Biol 5:e214

Fluttert M, Dalm S, Oitzl MS (2000) A refined method for sequential blood sampling by tail incision in rats. Lab Anim 34:372-378

Garner B, Wood SJ, Pantelis C, van den Buuse M (2007) Early maternal deprivation reduces prepulse inhibition and impairs spatial learning ability in adulthood: no further effect of postpubertal chronic corticosterone treatment. Behav Brain Res 176:323-332

Gruss M, Braun K, Frey JU, Korz V (2008) Maternal separation during a specific postnatal time window prevents reinforcement of hippocampal long-term potentiation in adolescent rats. Neuroscience 152:1-7

Heim C, Nemeroff CB (2001) The role of childhood trauma in the neurobiology of mood and anxiety disorders: preclinical and clinical studies. Biol Psychiatry 49:1023-1039

Heim C, Newport DJ, Heit S, Graham YP, Wilcox M, Bonsall R, Miller AH, Nemeroff CB (2000) Pituitary-adrenal and autonomic responses to stress in women after sexual and physical abuse in childhood. JAMA 284:592-597

Janssen J, Hulshoff Pol HE, Lampe IK, Schnack HG, de Leeuw FE, Kahn RS, Heeren TJ (2004) Hippocampal changes and white matter lesions in early-onset depression. Biol Psychiatry 56:825831

Karst H, Karten YJ, Reichardt HM, de Kloet ER, Schutz G, Joels M (2000) Corticosteroid actions in hippocampus require DNA binding of glucocorticoid receptor homodimers. Nat Neurosci 3:977-978

Kempermann G (2005) Adult neurogenesis, stem cells and neuronal development in the adult brain. Oxford University Press, Oxford

Kessler RC, McGonagle KA, Swartz M, Blazer DG, Nelson CB (1993) Sex and depression in the National Comorbidity Survey. I: lifetime prevalence, chronicity and recurrence. J Affect Disord 29:85-96

Kitamura T, Saitoh Y, Takashima N, Murayama A, Niibori Y, Ageta H, Sekiguchi M, Sugiyama H, Inokuchi K (2009) Adult neurogenesis modulates the hippocampus-dependent period of associative fear memory. Cell 139:814-827

LeDoux JE, Iwata J, Cicchetti P, Reis DJ (1988) Different projections of the central amygdaloid nucleus mediate autonomic and behavioral correlates of conditioned fear. J Neurosci 8:25172529

Lehmann J, Feldon J (2000) Long-term biobehavioral effects of maternal separation in the rat: consistent or confusing? Rev Neurosci 11:383-408
Lehmann J, Russig H, Feldon J, Pryce CR (2002) Effect of a single maternal separation at different pup ages on the corticosterone stress response in adult and aged rats. Pharmacol Biochem Behav 73:141-145

Lephart ED, Watson MA (1999) Maternal separation: hypothalamicpreoptic area and hippocampal calbindin-D28K and calretinin in male and female infantile rats. Neurosci Lett 267:41-44

Leppanen JM (2006) Emotional information processing in mood disorders: a review of behavioral and neuroimaging findings. Curr Opin Psychiatry 19:34-39

Leuner B, Gould E (2010) Structural plasticity and hippocampal function. Annu Rev Psychol 61(111-40):C1-C3

Levine S (2001) Primary social relationships influence the development of the hypothalamic-pituitary-adrenal axis in the rat. Physiol Behav 73:255-260

Levine S, Huchton DM, Wiener SG, Rosenfeld P (1991) Time course of the effect of maternal deprivation on the hypothalamicpituitary-adrenal axis in the infant rat. Dev Psychobiol 24:547558

Llorente R, Gallardo ML, Berzal AL, Prada C, Garcia-Segura LM, Viveros MP (2009) Early maternal deprivation in rats induces gender-dependent effects on developing hippocampal and cerebellar cells. Int J Dev Neurosci 27:233-241

Lucassen PJ, Meerlo P, Naylor AS, van Dam AM, Dayer AG, Fuchs E, Oomen CA, Czeh B (2010a) Regulation of adult neurogenesis by stress, sleep disruption, exercise and inflammation: implications for depression and antidepressant action. Eur Neuropsychopharmacol 20:1-17

Lucassen PJ, Stumpel MW, Wang Q, Aronica E (2010b) Decreased numbers of progenitor cells but no response to antidepressant drugs in the hippocampus of elderly depressed patients. Neuropharmacology 58:940-949

Mayer JL, Klumpers L, Maslam S, de Kloet ER, Joels M, Lucassen PJ (2006) Brief treatment with the glucocorticoid receptor antagonist mifepristone normalises the corticosterone-induced reduction of adult hippocampal neurogenesis. J Neuroendocrinol 18:629-631

McEwen BS (2003) Early life influences on life-long patterns of behavior and health. Ment Retard Dev Disabil Res Rev 9:149-154

Mello PB, Benetti F, Cammarota M, Izquierdo I (2009) Physical exercise can reverse the deficit in fear memory induced by maternal deprivation. Neurobiol Learn Mem 92:364-369

Morris R (1984) Developments of a water-maze procedure for studying spatial learning in the rat. J Neurosci Meth 11:47-60

Muller MB, Lucassen PJ, Yassouridis A, Hoogendijk WJ, Holsboer F, Swaab DF (2001) Neither major depression nor glucocorticoid treatment affects the cellular integrity of the human hippocampus. Eur J Neurosci 14:1603-1612

Oitzl MS, Workel JO, Fluttert M, Frosch F, De Kloet ER (2000) Maternal deprivation affects behaviour from youth to senescence: amplification of individual differences in spatial learning and memory in senescent Brown Norway rats. Eur J Neurosci 12:3771-3780

Oomen CA, Mayer JL, de Kloet ER, Joels M, Lucassen PJ (2007) Brief treatment with the glucocorticoid receptor antagonist mifepristone normalizes the reduction in neurogenesis after chronic stress. Eur J Neurosci 26:3395-3401

Oomen CA, Girardi CE, Cahyadi R, Verbeek EC, Krugers H, Joels M, Lucassen PJ (2009) Opposite effects of early maternal deprivation on neurogenesis in male versus female rats. PLoS ONE 4: e3675

Oomen CA, Soeters H, Audureau N, Vermunt L, van Hasselt FN, Manders EM, Joels M, Lucassen PJ, Krugers H (2010) Severe early life stress hampers spatial learning and neurogenesis, but improves hippocampal synaptic plasticity and emotional learning under high-stress conditions in adulthood. J Neurosci 30:6635-6645 
Paxinos G, Watson C (1986) The rat brain in stereotaxic coordinates, 2nd edn. Academic, New York

Petersen A, Wortwein G, Gruber SH, Mathe AA (2008) Escitalopram reduces increased hippocampal cytogenesis in a genetic rat depression model. Neurosci Lett 436:305-308

Phillips RG, LeDoux JE (1992) Differential contribution of amygdala and hippocampus to cued and contextual fear conditioning. Behav Neurosci 106:274-285

Plotsky PM, Meaney MJ (1993) Early, postnatal experience alters hypothalamic corticotropin-releasing factor (CRF) mRNA, median eminence CRF content and stress-induced release in adult rats. Brain Res Mol Brain Res 18:195-200

Pryce CR, Feldon J (2003) Long-term neurobehavioural impact of the postnatal environment in rats: manipulations, effects and mediating mechanisms. Neurosci Biobehav Rev 27:57-71

$\mathrm{Pu}$ Z, Krugers HJ, Joels M (2007) Corticosterone time-dependently modulates beta-adrenergic effects on long-term potentiation in the hippocampal dentate gyrus. Learn Mem 14:359-367

Pugh CR, Tremblay D, Fleshner M, Rudy JW (1997) A selective role for corticosterone in contextual-fear conditioning. Behav Neurosci 111:503-511

Rao U, Chen LA, Bidesi AS, Shad MU, Thomas MA, Hammen CL (2010) Hippocampal changes associated with early-life adversity and vulnerability to depression. Biol Psychiatry 67:357-364

Rodrigues SM, LeDoux JE, Sapolsky RM (2009) The influence of stress hormones on fear circuitry. Annu Rev Neurosci 32:289313

Rosenfeld P, Suchecki D, Levine S (1992) Multifactorial regulation of the hypothalamic-pituitary-adrenal axis during development. Neurosci Biobehav Rev 16:553-568

Sahay A, Hen R (2007) Adult hippocampal neurogenesis in depression. Nat Neurosci 10:1110-1115

Santarelli L, Saxe M, Gross C, Surget A, Battaglia F, Dulawa S, Weisstaub N, Lee J, Duman R, Arancio O, Belzung C, Hen R (2003) Requirement of hippocampal neurogenesis for the behavioral effects of antidepressants. Science 301:805-809

Saxe MD, Battaglia F, Wang JW, Malleret G, David DJ, Monckton JE, Garcia AD, Sofroniew MV, Kandel ER, Santarelli L, Hen R, Drew MR (2006) Ablation of hippocampal neurogenesis impairs contextual fear conditioning and synaptic plasticity in the dentate gyrus. Proc Natl Acad Sci U S A 103:17501-17506

Scharfman H (2007) The dentate gyrus, a comprehensive guide to structure, function and clinical implications. Elsevier, Amsterdam

Schenk F, Morris RG (1985) Dissociation between components of spatial memory in rats after recovery from the effects of retrohippocampal lesions. Exp Brain Res 58:11-28

Schmidt M, Enthoven L, van Woezik JH, Levine S, de Kloet ER, Oitzl MS (2004) The dynamics of the hypothalamic-pituitary-adrenal axis during maternal deprivation. J Neuroendocrinol 16:52-57
Sheline YI, Sanghavi M, Mintun MA, Gado MH (1999) Depression duration but not age predicts hippocampal volume loss in medically healthy women with recurrent major depression. J Neurosci 19:5034-5043

Stanton ME, Gutierrez YR, Levine S (1988) Maternal deprivation potentiates pituitary-adrenal stress responses in infant rats. Behav Neurosci 102:692-700

Stockmeier CA, Mahajan GJ, Konick LC, Overholser JC, Jurjus GJ, Meltzer HY, Uylings HB, Friedman L, Rajkowska G (2004) Cellular changes in the postmortem hippocampus in major depression. Biol Psychiatry 56:640-650

Surget A, Saxe M, Leman S, Ibarguen-Vargas Y, Chalon S, Griebel G, Hen R, Belzung C (2008) Drug-dependent requirement of hippocampal neurogenesis in a model of depression and of antidepressant reversal. Biol Psychiatry 64:293-301

Ustun TB (2000) Cross-national epidemiology of depression and gender. J Gend Specif Med 3:54-58

Uysal N, Ozdemir D, Dayi A, Yalaz G, Baltaci AK, Bediz CS (2005) Effects of maternal deprivation on melatonin production and cognition in adolescent male and female rats. Neuro Endocrinol Lett 26:555-560

van Praag H, Kempermann G, Gage FH (1999) Running increases cell proliferation and neurogenesis in the adult mouse dentate gyrus. Nat Neurosci 2:266-270

Videbech P, Ravnkilde B (2004) Hippocampal volume and depression: a meta-analysis of MRI studies. Am J Psychiatry 161:19571966

Vythilingam M, Heim C, Newport J, Miller AH, Anderson E, Bronen R, Brummer M, Staib L, Vermetten E, Charney DS, Nemeroff CB, Bremner JD (2002) Childhood trauma associated with smaller hippocampal volume in women with major depression. Am J Psychiatry 159:2072-2080

Wisden W, Laurie DJ, Monyer H, Seeburg PH (1992) The distribution of 13 GABAA receptor subunit mRNAs in the rat brain. I. Telencephalon, diencephalon, mesencephalon. J Neurosci 12:1040-1062

Workel JO, Oitzl MS, Fluttert M, Lesscher H, Karssen A, de Kloet ER (2001) Differential and age-dependent effects of maternal deprivation on the hypothalamic-pituitary-adrenal axis of brown Norway rats from youth to senescence. J Neuroendocrinol 13:569-580

Zhang LX, Levine S, Dent G, Zhan Y, Xing G, Okimoto D, Kathleen Gordon M, Post RM, Smith MA (2002) Maternal deprivation increases cell death in the infant rat brain. Brain Res Dev Brain Res 133:1-11

Zhou M, Conboy L, Sandi C, Joels M, Krugers HJ (2009) Fear conditioning enhances spontaneous AMPA receptor-mediated synaptic transmission in mouse hippocampal CA1 area. Eur $\mathrm{J}$ Neurosci 30:1559-1564 